\title{
Idiopathic Pulmonary Fibrosis in A Young Patient with Strong Family Background
}

\author{
Ralph Nehme ${ }^{1 *}$ and Stephanie J Mitri ${ }^{2}$ \\ ${ }^{1}$ Pulmonary and Critical Care Physician, Interventional Pulmonologist at Lebanese American University Rizk Hospital (LAUMCRH), Lebanon \\ ${ }^{2}$ Chief fellow of pulmonary and critical care medicine at Lebanese American University-Rizk and St John Hospitals, Lebanon
}

Submission: February 02, 2022; Published: February 11, 2022

*Corresponding author: Ralph Nehme, Pulmonary and Critical Care Physician, Lebanese American University (LAU), Zahar Street Ashrafieh, Beirut, Lebanon

\section{Abstract}

Background: Idiopathic pulmonary fibrosis (IPF) is the most common form of interstitial lung disease. It's a chronic, progressive and often fatal disease. The etiology, pathophysiology and predisposing factors of IPF are still not fully understood. Genetic mutations leading to the disease are sometimes among the underlying predisposing factors leading to the entity known as familial pulmonary fibrosis (FPF). FPF is a rare entity and often overlooked. Not much data is available on the subject in the literature. For that reason, it's important to increase awareness about this disease.

Case presentation: In the following article, we report the case of a young patient presenting with a fibrosing lung disease that turns out being a familial pulmonary fibrosis. This case report goes over the challenges faced with the diagnosis, the approach for treatment and the genetic counseling in FPF.

Conclusion: FPF is a rare disease with potential severe consequences for the patient. A high level of suspicions is required when making the diagnosis and potential genetic testing of family members might be required.

Keywords: Idiopathic pulmonary fibrosis; Familial pulmonary fibrosis; SPFTA2; Familial; Inheritance

Abbreviations: IPF: Idiopathic Pulmonary Fibrosis; FPF: Familial Pulmonary Fibrosis; ILD: Interstitial Lung Disease; IPs: Interstitial Pneumonias; UIP: Usual Interstitial Pneumonia; TLC: Total Lung Capacity; BAL: Bronchoalveolar lavage; HRCT: High-Resolution Computed Tomography; MDT: Multidisciplinary Team; SFTPC: Surfactant Proteins C; SFTPA: Surfactant Proteins A

\section{Case Report}

\section{Background}

Interstitial lung disease (ILD), also known as diffuse parenchymal lung disease, is a collective term that refers to a large number of acute and chronic lung disorders. Among these disorders are the idiopathic interstitial pneumonias (IPs), a heterogeneous group of chronic lung conditions of unknown aetiology that includes Idiopathic Pulmonary Fibrosis (IPF). It is crucial to separate IPF from other IPs due to differences in prognosis [1] and response to treatment [2]. IPF risk increases with age and smoking, having a predilection towards the male gender. IPF is associated with a histopathologic and/or radiologic pattern termed usual interstitial pneumonia (UIP) [3]. The etiology is still unknown, and it is thought that a multitude of factors may play a role, some of them being environmental and genetic. Familial pulmonary fibrosis (FPF) is defined by the presence of two cases or more of fibrosing pulmonary disease in the same family. It is often related to mutations in different types of genes.

\section{Case Presentation}

A 33-year-old non-smoker previously healthy male patient, presented for dyspnea mMRC1 with occasional dry cough. His symptoms were present for many months. He had no workrelated exposure and did not have any pets or birds. He takes no chronic medication. His mother died from lung cancer. He was healthy looking and well built. His SpO2 was $96 \%$ on room air, Blood pressure 120/70, heart rate of $85 / \mathrm{min}$ and regular. He had bilateral upper and lower lobes crackles on auscultation. His skin, abdominal, musculoskeletal exam were normal. He did not suffer from any hearing or vision problems.

Chest CT scan showed bilateral sub-pleural reticular septal thickening with traction bronchiectasis, honeycombing and some ground glass opacities. A craniocaudal gradient was present. In the mediastinum, bilateral mediastinal and hilar non-significantly enlarged lymph nodes were present (Figures 1A, 1B and 1C). Blood workup wasn't suggestive of any specific diagnosis: No blood 
eosinophilia, normal IgE, ACE levels, autoimmune and vasculitis workup. Pulmonary function tests showed a restrictive pattern with a total lung capacity (TLC) of 4.44L (58\% of the predicted value), FEV1 of $2.90 \mathrm{~L}$ ( $65 \%$ of the predicted value), FEV1/FVC 86.99 and a markedly reduced DLCO of $34 \%$.

Figure 1A
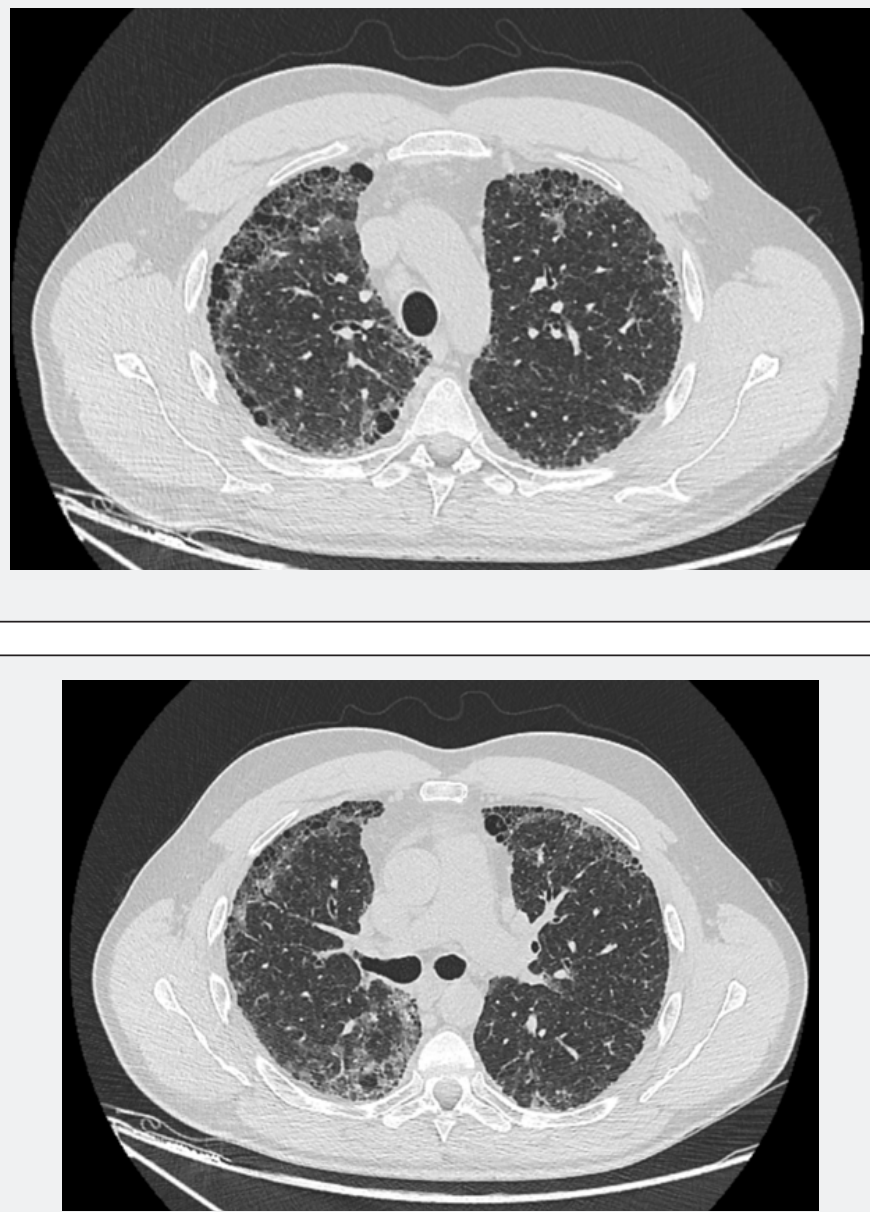

Figure 1B

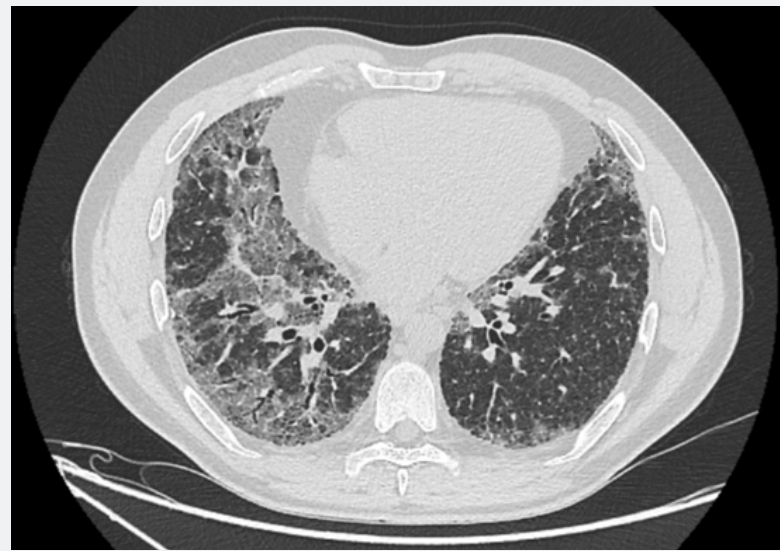

Figure 1C

Figures 1A, 1B and 1C: The patient's HRCT showing bilateral sub-pleural reticular septal thickening with traction bronchiectasis, honeycombing and ground glass opacities. 
EBUS-FNA of the right lower paratracheal as well as the subcarinal lymph node stations were normal. Bronchoalveolar lavage (BAL) was lymphocytic predominant. BAL cultures were negative. Cytology and bronchial biopsies were normal. Given the patient's young age, the significant changes on his pulmonary function tests, and the lack of definitive diagnosis, a surgical lung biopsy was done. It showed an advanced fibrotic interstitial lung disease most closely resembling UIP, with associated foci of follicular lymphoid hyperplasia/follicular bronchiolitis. This pathological diagnosis was confirmed by two other readings in two different specialized institutions.

Upon receiving this pathological diagnosis in a very young patient, further questioning was done. It revealed a strong family history for lung disease. His mother died at the age of 48 from lung cancer. His aunt, a 62-year-old non-smoker was diagnosed with an ILD two years ago. His mother's cousin and her son were diagnosed with lung cancer and ILD respectively. Another mother's cousin underwent the first lung transplant in Lebanon in 1997 due to advanced lung fibrosis. His maternal great grandfather and his sister along with three of her children died from lung related diseases. The patient underwent genetic testing that showed he harboured the mutation c.697T>A p. (Trp233Arg) in the SFTPA2 gene. The patient was started on Nintedanib $150 \mathrm{mg}$ PO bid. He is being followed clinically, radiologically and functionally. Genetic counselling will be done to plan for the future of his disease progression.

\section{Discussion}

IPF is an incapacitating disease with high morbidity and low survival. Three US studies generated a close approximation of costs per patient at around US\$20,000 [4]. IPF remains to be an increasing public health threat. It impacts both patients and health care workers considerably. The incidence of IPF appears to be increasing to around 3-9 per 100000 per year [5]. In North America, two studies estimated the prevalence between 42.7 [6] and 63 [7] patients per 100,000 population while a more recent Canadian study reported the prevalence to be as high as $115 / 100,000$. Progressive fibrosing interstitial lung diseases have a natural history of gradually decreasing lung function, coupled with a progressive increase in symptoms and decline in quality of life, leading ultimately to early morbidity and mortality [8].

With respect to life expectancy of IPF patients, the mean survival is estimated to be $2-5$ years from the time of diagnosis Mortality rates are estimated at 64.3 deaths per million in men and 58.4 deaths per million in women [9]. The diagnosis of IPF is usually made in older individuals in their sixth or seventh decade [10]. Symptoms range from a dry cough to chronic dyspnea on exertion. Bibasilar end-inspiratory crackles and finger clubbing are frequently found on physical exam [11]. The typical highresolution computed tomography (HRCT) presentation of IPF is the UIP pattern which includes bilateral peripheral, basilar predominant reticular infiltrates associated with honeycombing and traction bronchiectasis [12]. It is important to have the HRCT data interpreted by an experienced radiologist in the field of ILDs [13].

In order to have the best diagnostic yield for patients with suspected IPF as well as any other ILD, a multidisciplinary team (MDT) assessment of these patients by experienced physicians from multiple specialties (pulmonologists, radiologists, pathologists...) is the ideal diagnostic approach [14]. However, despite MDT approach, the definitive diagnosis of IPF sometimes remains uncertain, requiring the need for a surgical lung biopsy [15]. Nintedanib and Pirfenidone are the two main antifibrotic drugs that have been validated for the treatment of IPF. They slow the decline in lung function and reduce the risk for acute exacerbation which increase patients' morbidity and mortality. Analyses of pooled data from clinical trials and observational studies suggest that antifibrotic treatments improve life expectancy [16].

FPF is defined as idiopathic pulmonary fibrosis that is present in two or more family members. It is hereditary and the most common mode of transmission is autosomal dominant with variable penetrance [17]. This familial disease entails a younger age of presentation, no gender predominance, a more rapid progression of disease and the smoking habit as a strong predisposing factor. The prevalence of the disease is not very well known, it is estimated to be approximately 1.34 cases per 106 population according to some studies [18]. FPF patients who have a DLCO below $40 \%$ of predicted or a Forced Vital Capacity declining by more than $10 \%$ per year have a worst outcome and a reduced survival [19]. Patients with FPF also have a $40 \%$ increased risk for death or lung transplantation when compared with patients with sporadic IPF [20].

Multiple radiological patterns exist in patients with FPF. The most frequent presentation is the UIP pattern but other radiologic presentations like nonspecific interstitial pneumonia, ground glass opacities mimicking hypersensitivity pneumonitis and rarely organizing pneumonia can be seen. Finally, some HRCT patterns remain unclassifiable [21]. Mutations in genes like the surfactant proteins $\mathrm{C}$ and A genes (SFTPC and SFTPA), the ABCA3 gene that encodes for an intracellular SFTPC carrier, the TERT and TERC genes encoding for the telomerase complex and the MUC5B polymorphism (rs35705950) are responsible for about 20\% of all FPF cases; while many other probable genetic mutations are still unknown [22]. These mutations have also been implicated in other diseases.

For example, surfactant gene mutations have been involved in cystic fibrosis disease. ABCA2: transporter gene mutations have been correlated with senile plaque development. Mutation in SFTPA2 was correlated with IPF and lung cancer [23]. Mutations in the TERT gene have been associated with an increased risk of 
various cancers, especially melanoma and acute myeloid leukemia [24]. The most frequent mode of inheritance as mentioned before is autosomal dominant with anticipation; meaning that the younger generations tend to manifest the disease earlier [21]. Other means of transmission like autosomal recessive or X-linked have been described depending on the mutation [21]. Thus, if FPF is suspected, a detailed familial screening should be discussed.

The treatments of FPF, especially with UIP presentation, is similar to non-familial IPF but with much more limited evidence and data regarding their efficiency due to the scarce number of cases. It is suggested that treatment response might be worse for patient with FPF compared to those with non-familial IPF. In fact, a multicenter retrospective study conducted in Europe included 33 patients with lung fibrosis and a TERT or TERC mutation, failed to show any effect of pirfenidone on lung function decline [25]. Genetic testing of asymptomatic family members of FPF patients is still debatable for multiple reasons.

First, sequencing results are often neither positive nor negative; instead, sequencing commonly reveals variants of unknown significance. In addition, it is possible that some patients who have a negative genetic test result may harbor yetto-be-identified variants that predispose to disease. Second, the cost of genetic testing can be substantial and is often deferred to the patient. Third, genetic testing itself may have a psychological impact on patients and their relatives. For all these reasons, genetic screening of asymptomatic individuals should be delicately approached and be ideally done in centers experienced in taking care of the tested patients both physically and psychologically [26].

\section{Conclusion}

FPF is a rare disease with potential severe consequences for the patient. Patients with FPF are frequently young and can present with different types of interstitial lung involvement, one of the most frequent being a UIP presentation. A high level of suspicions is required when making the diagnosis since many of these patients don't have a good response to anti-fibrotic medication and thus might need a close follow-up for referral to a lung transplantation program. Potential genetic testing of family members might be required.

\section{References}

1. Wells AU, Flaherty KR, Brown KK, Inoue Y, Devaraj A, et al. (2020) Nintedanib in patients with progressive fibrosing interstitial lung diseases-subgroup analyses by interstitial lung disease diagnosis in the INBUILD trial: a randomised, double-blind, placebo-controlled, parallel-group trial. Lancet Respir Med 8(5): 453-460.

2. Kim DS, Park JH, Park BK, Lee JS, Nicholson AG, et al. (2006) Acute exacerbation of idiopathic pulmonary fibrosis: frequency and clinical features. Eur Respir J 27(1): 143-50.

3. Raghu G, Collard HR, Egan JJ, Martinez FJ, Behr J, et al. (2011) An official ATS/ERS/JRS/ALAT statement: idiopathic pulmonary fibrosis: evidence-based guidelines for diagnosis and management. Am J Respir Crit Care Med 183(6): 788-824.

4. Collard HR, Ward AJ, Lanes S, C Hayflinger D, Rosenberg DM, et al (2012) Burden of illness in idiopathic pulmonary fibrosis. J Med Econ 15(5): 829-835

5. Lai CC, Wang CY, Lu HM, Likwang C, Nai-Chi T, et al. (2012) Idiopathic pulmonary fibrosis in Taiwan - A population-based study. Respir Med 106(11): 1566-1574.

6. Raghu G, Weycker D, Edelsberg J, Bradford WZ, Oster G (2006) Incidence and prevalence of idiopathic pulmonary fibrosis. Am J Respir Crit Care Med 174(7): 810-816

7. Fernandez Perez ER, Daniels CE, Schroeder DR, St Sauver J, Hartman TE, et al. (2010) Incidence, prevalence, and clinical course of idiopathic pulmonary fibrosis: a population-based study. Chest 137(1): 129-137

8. Wijsenbeek M, Kreuter M, Fischer A, Mounir B, Zouad-Lejour L, et al. (2018) Non-IPF progressive fibrosing interstitial lung disease (PFILD): the patient journey. Am J Respir Crit Care Med 197: A168.

9. Nalysnyk L, Cid-Ruzafa J, Rotella P, Dirk Esser (2012) Incidence and prevalence of idiopathic pulmonary fibrosis: review of the literature. Eur Respir Rev 21(126): 355-361.

10. Raghu G, Weycker D, Edelsberg J, Bradford WZ, Oster G (2006) Incidence and prevalence of idiopathic pulmonary fibrosis. Am J Respir Crit Care Med 174(7): 810-816

11. Douglas WW, Ryu JH, Schroeder DR (2000) Idiopathic pulmonary fibrosis: Impact of oxygen and colchicines, prednisone, or no therapy on survival. Am J Respir Crit Care Med 161(4 Pt 1): 1172-1178.

12. Raghu G, Collard HR, Egan JJ, Fernando JM, Juergen B, et al. (2011) An official ATS/ERS/JRS/ALAT statement: Idiopathic pulmonary fibrosis: Evidence-based guidelines for diagnosis and management. Am J Respir Crit Care Med 183(6): 788-824

13. Raghu G, Mageto YN, Lockhart D, Schmidt RA, Wood DE, et al. (1999) The accuracy of the clinical diagnosis of new-onset idiopathic pulmonary fibrosis and other interstitial lung disease: A prospective study. Chest 116(5): 1168-1174.

14. Travis WD, Costabel U, Hansell DM, Talmadge EK, David AL, et al. (2013) An Official American Thoracic Society/European Respiratory Society Statement: Update of the international multidisciplinary classification of the idiopathic interstitial pneumonias. Am J Respir Crit Care Med 188(6): 733-748

15. Kim DS, Collard HR, King TE (2006) Classification and natural history of the idiopathic interstitial pneumonias. Proc Am Thorac Soc 3(4): 285-292.

16. Maher TM, Strek ME (2019) Antifibrotic therapy for idiopathic pulmonary fibrosis: time to treat. Respir Res 20(1): 205.

17. Wytrychowski K, Hans-Wytrychowska A, Nowakowska B (2013) Familial idiopathic pulmonary fibrosis. Adv Exp Med Biol 788: 363367.

18. Marshall RP, Puddicombe A, Cookson WO, Laurent GJ (2000) Adult familial cryptogenic fibrosing alveolitis in the United Kingdom. Thorax 55(2): 143-146

19. Du Bois RM, Weycker D, Albera C, Bradford WZ, Costabel U, et al (2011) Forced vital capacity in patients with idiopathic pulmonary fibrosis: test properties and minimal clinically important difference. Am J Respir Crit Care Med 184(12): 1382-1389.

20. Cutting C, Bowman WS, Dao N, Janelle VP, Christine KG, et al. (2021) Family history of pulmonary fibrosis predicts worse survival in patients with interstitial lung disease. Chest 159(5): 1913-1921. 
21. Borie R, Kannengiesser C, Nathan N, Tabeze L, Pradere P, et al. (2015) Familial pulmonary fibrosis. Rev Mal Respir 32(4): 413-34.

22. Borie, R, Crestani B (2019) Familial pulmonary fibrosis: a world without frontiers. J Bras Pneumol 45(5): e20190303.

23. Wang Y, Kuan PJ, Xing C, Cronkhite JT, Torres F, et al. (2009) Genetic defects in surfactant protein $\mathrm{A} 2$ are associated with pulmonary fibrosis and lung cancer. Am J Hum Genet 84(1): 52-59.
24. Arish N, Petukhov D, Wallach-Dayan SB (2019) The Role of Telomerase and Telomeres in Interstitial Lung Diseases: From Molecules to Clinical Implications. Int J Mol Sci 20(12): 2996.

25. Justet A, Thabut G, Manali E, Molina MM, Kannengiesser C, et al. (2018) Safety and efficacy of pirfenidone in patients carrying telomerase complex mutation. Eur Respir J 51(3): 1701875.

26. Zhang D, Newton CA (2021) Familial Pulmonary Fibrosis: Genetic Features and Clinical Implications. Chest 160(5): 1764-1773.

\section{Your next submission with Juniper Publishers} will reach you the below assets

- Quality Editorial service

- Swift Peer Review

- Reprints availability

- E-prints Service

- Manuscript Podcast for convenient understanding

- Global attainment for your research

- Manuscript accessibility in different formats ( Pdf, E-pub, Full Text, Audio)

- Unceasing customer service

Track the below URL for one-step submission https://juniperpublishers.com/online-submission.php 